\title{
Tokat İlinin Kentsel Rekabet Edebilirliğinin TR83 Bölgesi Kapsamında Değerlendirilmesi*
}

\author{
Mustafa Necati ÇOBAN**
}

\begin{abstract}
$\ddot{O} Z$
Ülkelerin dünden bugüne bölgesel politika kavramına bakış açıları değişmiş, bu değişimle beraber sadece geri kalmış bölgeler değil, tüm bölgeler ülkelerce belirlenen bölgesel politikanın odak noktasına yerleştirilmiștir. Bu değişimle beraber ülkelerce geri kalmış bölgelerin kalkındırılması hedefinin dışında diğer bölgelerin de rekabet edebilirliğinin artırılmasına yönelik plan, program ve hedefler belirlenmektedir.

Büyüme, verimlilik, rekabet ve performans gibi kavramlar ihtiva eden bölgesel rekabet kavramı uluslararası ekonomik kuruluşlarca da önemsenen ve bölgelerarası rekabetin artırılmasına hizmet eden önemli bir husustur. Bölgelerarası rekabetin artırlması ile ülke genelinde refah artacak, geliş̧me sağlanacaktır.

Bölgelerin büyüme, verimlilik, performans, yenilikçilik anlamında başarı gösterip rekabetçi bölgeler olarak sinıflandırılmasinda rekabetçi kentlerin rolü büyüktür. Bu bağlamda bölgesel rekabeti sağlamada ilk olarak kentsel rekabet edebilirliği tesis etmek, rekabetçi kentler oluşturmak oldukça önem arz etmektedir.

Çalı̧̧mada, Tokat ilinin kentsel rekabet edebilirliği TR83 bölgesi bağlamında ele alınacak, TR83 bölgesinde yer alan Amasya, Çorum, Samsun gibi illerle karşılaştırmalı olarak bir değerlendirme yapılacaktır. Çalışmada TR83 bölgesinde yer alan illerin kentsel rekabet gücünü belirlemede 'beşeri sermaye ve yaşam kalitesi' , 'markalaşma becerisi ve yenilikçilik', 'ticaret becerisi' ve 'erişilebilirlik' olmak üzere dört endeks sınıflandırmast altında 35 değişken kullanılacaktır. Illk olarak değişkenlerin normalize edilmesi sağlanacak daha sonra da belirtilen formüllerle analiz gerçekleştirilecektir.
\end{abstract}

Anahtar Kelimeler: kentlerararası rekabet, bölgesel rekabet, rekabet edebilirlik, kentsel rekabet edebilirlik, TR83.

JEL Sinıflandırması: O18, P25, O57, O52, R15.

\section{The Evaluation of Urban Competitiveness of Tokat Province in the Scope of TR83 Region}

\begin{abstract}
From now on, the perspective of the countries on the concept of regional politics has changed, and with this change, not only the backward regions, but all the regions have been placed in the focus of the regional politics which is determined by the countries. Along with this change, plans, programs and targets are set to increase the competitiveness of other regions besides the goal of development of the countries that are lagging behind.

The concept of regional competition, which includes concepts such as growth, productivity, competition and performance, is an important issue that is important in international

\footnotetext{
* Bu çalışma, 08-10 Nisan 2017 tarihleri arasında IKKSAD tarafından Batum'da düzenlenen 1. Uluslararası Mesleki ve Teknik Bilimler Kongresi’nde sözlü bildiri olarak sunulmuştur.

** Dr. Öğr. Üyesi, Tokat Gaziosmanpaşa Üniversitesi İktisadi ve İdari Bilimler Fakültesi, İktisat Bölümü, necati.coban@gop.edu.tr, ORCID bilgisi: 0000-0003-2839-4403.
}

(Makale Gönderim Tarihi: 16.02.2019 / Yayına Kabul Tarihi:15.08.2019) 
economic organizations and serves to increase competition between regions. Increasing competition among regions will increase prosperity in the country and improve development.

The role of competitive cities is great when the regions are successful in terms of growth, productivity, performance, innovation, and are classified as competitive regions. In this context, it is very important to establish urban competitiveness and create competitive cities in the first place in regional competitiveness.

In the study, the urban competitiveness of Tokat province will be considered in the context of TR83 region, and an evaluation will be made comparatively in the TR83 region such as Amasya, Çorum and Samsun. In the study, 35 variables will be used in determining the urban competitive power of the TR83 regions under the four index classifications as 'human capital and quality of life', 'branding skill and innovation', 'trade skill' and 'accessibility'.First, the variables will be normalized and then analyzed using the formulas specified.

Key Words: Intercity Competition, Regional competition, Competitiveness, Urban competitiveness, TR83.

JEL Classification: O18, P25, O57, O52, R15.

\section{GíRIŞ}

Üretim, tüketim, finans ve benzeri iktisadi değişkenlerin küreselleşmesiyle beraber modern dünya ekonomisinde gözle görülür değişiklikler gerçekleşmiştir. Ulus ötesi şirketler, karlarını maksimize etme ve dünya üzerindeki kaynakları etkin kullanabilme amacıyla teknoloji ve sermaye gibi unsurlardan tam anlamiyla yararlanma yoluna gitmektedirler (Shen, 2014: 19).

Küreselleşme ile beraber ülkelerin gelişmesinde önem kazanan kentler ve bu kentlerden oluşan bölgeler, ülkelerin uluslararası kapsamda rekabet edebilmesi yönünden önemli unsurlar olarak nitelendirilmektedir. Bu kavramlar içerisinde en temel birim olarak kentlerin birbiriyle rekabet edebilir nitelikte olması, bölgelere ve böylelikle ülke geneline makroekonomik kavramlar kapsamında olumlu etki gerçekleştirebilecektir.

Kentler birbirleriyle farklı şekillerde rekabet gerçekleştirebilmektedirler. $\mathrm{Bu}$ rekabet şekilleri içerisinde en temel olanlarından birisi ürün pazarlarına yönelik olmakla beraber kentler kendilerine gerçekleştirilecek yatırımlar için cazibe merkezi olmaya çabalamakta ve devlet mekanizmasından gelebilecek fonlar için yarışmaktadırlar (Gordon, 1999: 1001).

Rekabetçi kentler ve rekabetçi bölgeler oluşturulması makroekonomik göstergelerde olumlu etkiler gerçekleştirebilmektedir. Kentlerdeki istihdam oranı, büyüme oranı, kentlerin altyapısal durumu, kentlerdeki ticaret yapabilme kolaylığ 1 , kentlerin ulaşılabilirliği, kentlerin yaratıcı ekonomik faaliyetleri ve markalaşma becerileri, endüstriyel konumu ve sunduğu yaşam kalitesi gibi göstergelerin olumlu seyretmesi aynı zamanda bütüne yansıyarak ülkelerin de diğer ülkelerle rekabet edebilmesine katkı sağlamaktadır.

Rekabetçi bir kent, yaratıcı ürünler geliştirebilen ve yaratıcı sektörlere yönelebilen, yaratıcı ekonomi unsurlarını gerçekleştirebilen bir kenttir. Rekabetçi bir kent aynı zamanda kent sakinlerine refah sağlama yeteneğine sahip bir kent olarak nitelendirilmektedir (Du vd, 2014: 3375).

Çalışmada Tokat ilinin kentsel rekabet edebilirliği TR83 bölgesi kapsamında araştırılmıştır. Bu kapsamda benzer çalışmalardan yararlanılarak 
kentsel rekabet edebilirlik endeksi oluşturulmuştur. Çalışmada TR83 bölgesinde yer alan illerin kentsel rekabet gücünü belirlemede 'beşeri sermaye ve yaşam kalitesi', 'markalaşma yeteneği ve yaratıcılık', 'ticaret becerisi' ve 'erişilebilirlik' olmak üzere dört endeks sınıflandırması altında 35 değişken kullanılmıştır. İlk olarak değişkenlerin normalize edilmesi sağlanmış daha sonra da belirtilen formüllerle analiz gerçekleştirilmiştir. Çalışmada, TR83 Bölgesi içerisinde yer alan Tokat ilinin rekabetçilik seviyesinin diğer illerle karşılaştırmalı olarak değerlendirilmesi ve bu bağlamda TR83 bölgesi kapsamında rekabet edebilme gücünün tespit edilmeye çalışılması amaçlanmaktadır.

\section{TEORIKK ÇERÇEVE}

Şehirlerin giderek birbirleriyle farklı seviyelerde rekabet etmeye başlaması, araştırmacıları rekabet avantajının belirleyicileri hususunda çalışmalar yapmaya yönelik teşvik etmektedir. Ulusal, bölgesel veya kentsel hangi nitelikte olursa olsun bir çok kalkınma stratejisi "ekonomiyi daha rekabetçi hale getirmek için neler yapılabilir” fikrinden yola çıkarak gerçekleşmeye başlamıştır (Begg, 1999: 795).

Kentlerin birbirleriyle rekabet edebilmeleri noktasında özellikle kentlerin beşeri sermaye ve yaşam kalitesi, markalaşma yeteneği ve yaratıcılık, ticaret becerisi ve erişilebilirlik olmak üzere dört farklı unsurun önemli rol oynadığ1 ifade edilmektedir.

\section{A.Beşeri Sermaye ve Yaşam Kalitesi}

Beşeri sermaye, ülkelerin gelişmişlik göstergelerinden birisi olup katma değer sağlayan önemli bir kavramdır. Kentler, beşeri sermayeyi çekmek için daha iyi koşullara sahip olmalı ve bu kapsamda yatırımlar gerçekleştirmelidir. Bu kapsamda fonlar tahsil edilmeli ve ekonomik gelişmeye katkı sağlanmalıdır (Morais, Migueis ve Camanho, 2013: 188).

Yaşam kalitesi ise genel itibariyle insanların istek ve ihtiyaçlarının gelişim düzeyi ve memnuniyet derecelerini yansıtan bir kavram olarak değerlendirilmektedir. Yaşam kalitesi bireylerin tükettikleri gıda kalitesini, kültürel gereksinimlerini, giyim kalitesini, sağlık hizmetlerinden yararlanma kalitesini, eğitim kalitesi vb kıstasları ifade eden sosyolojik bir tanımdır (Tsaurkubule, 2013: 105).

Bilgi, insan kaynaklarının en temel özelliğidir. Gelişmiş ve rekabetçi kentlerde bilginin mekansal organizasyonun önemli bir gücü olduğu ileri sürülmektedir. Neoklasik yaklaşım, ekonomik kalkınma kapsamındaki eşitsizlikleri açıklayan en önemli kavramın beşeri sermaye olduğunu savunmaktadır. Beşeri sermaye kapsamında zengin olmayan bir kent, kentsel olarak rekabet edemeyecektir (Ildiko, 2009: 1070-1071).

Kentlerin beşeri sermaye kapsamındaki birikimi ve sunduğu yaşam kalitesi rekabetçi kentler olarak değerlendirilebilmeleri kapsamında büyük önem taşımaktadır. Kentte yaşayan vatandaşların eğitim seviyelerinin yüksek oluşu, kentteki sağlık vb hizmetlerin yüksek standartlarda sağlanması, kentin sosyal olanaklarının fazla oluşu ve kentte yaşayan vatandaşların refah seviyelerinin 
yüksek oluşu ve benzeri faktörler kentlerin rekabet edebilirliği noktasında belirleyici rol oynamaktadır.

\section{B.Markalaşma Yeteneği ve Yaratıcılık}

Kentlerin rekabet edebilirliğinde kentlerin markalaşma becerilerinin yüksek olmasının ve yaratıcı ekonomi faaliyetlerine yatkın olmalarının belirli rol oynadığı aşikardır. Yaratıcı fikirlerin üretildiği ve bunların çeşitli yöntemlerle pazarlandığı kentler, rekabet edebilirlik noktasında ön plana çıkmaktadır.

Dünyanın her geçen gün daha fazla küreselleşmesiyle beraber şehirler arasında rekabet gelişmekte ve şehirler küresel pazarda reklamlarını yapmak için strateji geliştirmektedirler. Bu strateji, özellikle kültürel etkinlikler, kentlerin sahip oldukları tarihi mirasın restorasyonu ve ikonik yapıların inşası üzerinden gitmektedir (Riza, Doratli ve Fasli, 2011: 294).

Markalaşma yeteneği yüksek olan bir kentin iktisadi verimliliği, refah düzeyi ve sunduğu yaşam konforu yüksek olacaktır. Fakat kentsel markalaşmanın gerçekleştirilebilmesi ve geliştirilebilmesi için en önemli hususlardan birisi, kentin bilgi ekonomi kapsamında çağdaş bir seviyeyi yakalamış olmasıdır (Moradi, Zarabadi ve Majedi, 2018: 185-186).

Özgün fikirlerin ortaya atılması ve bu özgün, sıradışı fikirlerin sanat ve kültür ürünleri inşa etmede rol oynaması, bilimsel icatlar ve teknolojik yeniliklere öncülük etmesi ve bu kapsamda eserler üretilmesi yaratıcıllk olarak ifade edilmektedir (UNCTAD, 2008: 3).

Yaratıcılık, markalaşma becerisi ile beraber kullanılan bir kavram olmakla beraber birbirini tamamlayan kavramlardır. Rekabetçi kentler yaratıcı ekonomik faaliyetler gerçekleştirmekte başarılı ve markalaşmış kentlerdir.

\section{C.Ticaret Becerisi}

Ticaret, ülkelerin daha geniş yelpazedeki girdilere erişmesine olanak tanımakta ve bu kapsamda dışsal ölçek ekonomilerinin oluşmasına imkan tanımaktadır. Aynı zamanda ülkelerin dışa açıklık oranının artmasına ve böylelikle küresel ticaret entegrasyonunu gerçekleştirmesine katkıda bulunmaktadir (European Commission Directorate, 2009: 2-10).

İhracat ve ithalat rakamları, uluslararası alanda ülkelere avantaj veya dezavantaj sağlayabildiği gibi kentlerin ihracat ve ithalat rakamları da kendilerinin ticaret becerilerini göstermesi ve rekabet edebilirlik düzeyleri bakımından önem taşımaktadır.

Kentlerin ticaret edebilme yetisi, aynı zamanda kendi içerisinde barındırdığı sektörlerin etkinliğine ve verimliliğine de bağlıdır. Belirli sektörler bu kapsamda verim sağlamakta iken, bazı sektörler büyümeye katk1 sağlamayabilir. $\mathrm{Bu}$ kapsamda kentler kaynaklarını ve yatırımları verimli olan sektörlere aktarmalıdırlar.

Kentlerin rekabetçi bir nitelik taşıyabilmeleri için bu kentlerin iç talep potansiyeli, kamu yatırımları, ihracat hacimleri, açılan ve kapanan şirket sayıları, kullanılan vergi miktarı ve benzeri değişkenler önem arz etmektedir. 


\section{D.Erişilebilirlik}

Erişilebilirlik, rekabet edilebilirliğin temel faktörlerinden birisidir. Erişilebilirlik yönünden avantajlı olan kent veya bölgeler, hizmetlere daha kolay erişebilirler. Kentlerin rekabet edebilmelerinde ana etkenlerden birisi olan erişilebilirlik, ekonomik ve mekansal gelişim kapsamında bir ön koşul olarak nitelendirilmektedir (L'Hostis ve Bozzani, 2010: 1).

Ulaşım kavramını da kapsayan erişilebilirlik kavramı, kentlerin endüstriyel gelişimlerinde önemli rol oynamaktadır. Ulaşım kapsamında avantajlı konumda olan kentler, diğer kentlere nazaran daha hızlı gelişim gösterebilmektedirler. Kentlerin erişilebilir nitelikte olması, ticari faaliyetlerde maliyetlerin düşmesini sağlamakta ve endüstriyel olarak daha hızlı aşama kat edilmesine yardımcı olmaktadır.

Erişilebilirlik, aynı zamanda bilgi iletişim teknolojilerinin kullanımını da içermektedir. Bilgi iletişim teknolojilerinin gelişmiş olduğu kentler dijital ekonominin gereklerini yerine getiren ve çağa ayak uydurmuş modern şehirlerdir.

Erişilebilirlik değişkeni kapsamında kentlerin otoyol ağına bağlı olup olmadığı, limanların varlığı, demiryolu ağına sahip olup olmadığı, sahip olunan kent yolunun uzunluğu, havalimanı olup olmaması, ADSL abone sayısı ve haberleşme ve kamu sektörüne gerçekleştirilen yatırımların miktarı kentsel rekabet edebilirlik kapsamında önem arz etmektedir.

\section{LITERATÜR TARAMASI}

Kentsel rekabet, ekonomilerin büyümesini doğrudan veya dolaylı yoldan etkileyebilen, aynı zamanda bölgesel rekabete de katkıda bulunan önemli bir çalışma olanı olarak nitelendirilmektedir. Literatürde kentlerin rekabet edebilirliğiyle alakalı bir takım çalışmaların gerçekleştirildiği gözlemlenmektedir.

Shen (2004), yazmış olduğu makalede kentsel dönüşüm kapsamında kentsel rekabetçilik ve kentsel yönetim fikirlerini ele almıştır. Çalışmada Hong Kong'da değişen kentsel yönetişim ve HKSAR hükümetinin kentsel rekabet gücünü artırabilmek için gerçekleştirdiği girişimler araştırılmıştır. Çalışmada sonuç olarak HKSAR hükümetinin kentsel rekabetçiliği artırmaya yönelik girişimlerinin yetersiz olduğu, bununla beraber iş dünyasının ve toplumun aktif katılımının gerekli olduğu vurgulanmıştır.

Pengfei ve Qinghu (2006), yapmış oldukları çalışmada kent rekabetçiliğine yönelik karşılaş̧ırmalı bir analiz gerçekleştirmişlerdir. $\mathrm{Bu}$ kapsamda Dünya üzerindeki küresel özellik arz eden şehirler analize katılmıştır. $\mathrm{Bu}$ analize katılan şehirlerin kentsel rekabet edebilirlik puanları hesaplanmış ve karşılaştırma gerçekleştirilmiştir. Sonuç olarak Kuzey Amerika ve Avrupa'da bazı şehirlerin rekabet gücünün diğerlerine nazaran oldukça yüksek olduğu dile getirilmiş, bununla beraber rekabet gücündeki artış noktasında Asya'da yer alan şehirlerin diğer bölgedeki şehirlere göre daha üst seviyede olduğu sonucuna ulaşılmıştır.

Alkin, Bulu ve Kaya (2007), gerçekleştirmiş oldukları çalışmada Türkiye'de yer alan illerin rekabetçilik seviyelerini araştırmışlardır. Bu kapsamda iller arası rekabet endeksi oluşturulmuştur. Çalışma neticesinde İstanbul ili, 
rekabetçilik seviyesi en yüksek il olurken Ardahan ili rekabetçilik endeks değeri en düşük il olarak tespit edilmiştir.

Sinkiene (2009), yazmış olduğu makalede Litvanya' da yer alan şehirlerin rekabet edebilirliğinin temel faktörlerini belirlemeye yönelik bir araştırma gerçekleştirmiştir. Çalışmada sonuç olarak ülkeler ve bölgeler bazında oluşturulan rekabet edilebilirlik modellerinin aynı zamanda kent rekabetçiliğinin analizi kapsamında da uygulanabileceği kanısına varılmıştır.

Albayrak ve Erkut (2010), yayınladıkları makalede Türkiye'deki bölgesel rekabet gücünü analiz etmişlerdir. Bu kapsamda Türkiye'de yer alan bölgeler rekabet güçlerine göre kategorize edilmiş ve bu bölgeleri farklılaştıran özellikler tanımlanmıştır. Temel bileşen analizi ve hiyerarşik kümeleme analizi gerçekleştirilerek bölgesel rekabet gücü endeksi oluşturulmuştur. Çalışmada oluşturulan beş bölgesel rekabet grubunun rekabet güçleri ve küresel kapsamda rekabet edebilirliklerindeki farkl1lıklar dikkate alınarak bölgesel politikaların gerçekleştirilmesi gerektiği yönünde sonuca ulaşılmıştır.

Bruneckiene, Guzavicius ve Cincikaite (2010), gerçekleştirmiş oldukları çalışmada Litvanya'da yer alan şehirlerin kentsel rekabet edebilirliklerini araştırmışlardır. Bu kapsamda 2007-2009 yılları arası veriler kullanılarak Litvanya'daki 10 bölgeden 24 şehrin verileri analize dahil edilmiştir. Çalışma sonucunda Vilnius bölgesinde yer alan Trakai kenti kentsel rekabet edebilirlik puanı en yüksek şehir olarak belirlenmiştir.

Eroğlu ve Yalçın (2010), yazmış oldukları makalede kent rekabetçiliğine yönelik literatür taraması gerçekleştirmişlerdir. Bu kapsamda literatür taranarak 2010 yılına kadar olan kent rekabetçiliğine yönelik gerçekleştirilmiş çalışmalar irdelenmiştir.

Peng ve Zhanxin (2011), yapmış oldukları çalışmada Çin'in Shandong eyaletinde yer alan şehirlerin kentsel rekabet edebilirliklerini araştırmışlardır. Shandong eyaletinde yer alan 17 şehir Veri Zarflama Analizi gerçekleştirilerek analize katılmıştır. Gerçekleştirilen analiz neticesinde kentsel rekabet edebilirlik seviyesi en yüksek iki şehir sırasıyla Qingdao ve Jinan olmuştur.

Kwon, Kim ve Oh (2012), gerçekleştirmiş oldukları çalışmada Kore'de yer alan Ulsan, Daegu, Incheon, Gwangju, Daejeon ve Busan gibi büyük şehirlerin inovasyona dayalı kentsel rekabetçilik seviyelerini belirlemeyi amaçlamışlardır. Kentsel rekabetçilik puanları Analitik Hiyerarşi Süreci ile belirlenmiştir. Sonuç olarak inovasyona dayalı kentsel rekabetçilik puanı en yüksek olan şehrin Daejeon olduğu belirtilmiştir.

Ak (2013), gerçekleştirmiş olduğu çalışmada İzmir ilinin kentler arası rekabetçilik kapsamında konumunu araştırmıştır. Çalışmada kentler arası rekabetin teorik kapsamı ifade edilmiş ve İzmir'in rekabetçi yapısı tartışılmıştır. Sonuç olarak İzmir'in rekabet edebilme potansiyeli yüksek bir il olduğu ifade edilmiştir.

Papa, Gargiulo, Franco ve Russo (2014), yayınlamış oldukları çalışmada İtalyan şehirlerinin rekabetçilik yapıları ile akıllı şehir olma yapılarını kıyaslamıştır. Çalışma sonucunda akıllılık ve rekabetçilik yapılarının sıkı bir 
şekilde birbirine bağlı olduğu sonucuna ulaşılmıştır. Bir şehrin daha çekici ve daha rekabetçi olması için akıllı şehir olma gereksinimlerini yerine getirmesi gerekmektedir.

Guo, Liu, Li, Wang ve Chen (2015), gerçekleştirmiş oldukları çalışmada Çin'deki şehirleri kümelere ayırarak bu kümeler kapsamında rekabet edebilirlik kavramını araştırmışlardır. Çalışmada 2009 yılına ait veriler alınarak TOPSIS yöntemi kullanılmış ve 28 Çin kent kümesinden 141 kentin kentsel rekabet gücü belirlenmiştir. Çalışmada her grup için tavsiye ve önerilere yer verilmiştir. Çalışmada sonuç olarak kentsel rekabet edebilirlik değeri en yüksek şehir Suzhou olarak belirlenmiştir.

İpek ve Öksüz (2015), yapmış oldukları çalışmada Giresun ilinin kentsel rekabet gücünü DOKA kapsamında incelemişlerdir. Bu kapsamda "beşeri sermaye ve yaşam kalitesi" , "markalaşma becerisi ve yenilikçilik", "ticaret becerisi" ve "erişilebilirlik" olmak üzere dört endeks oluşturulmuş ve bu endekslere ait 35 değişken kullanılmıştır. Veriler ilk etapta normalize edilmiş ve daha sonrasında betimlenen formüllerle analiz gerçekleştirilmiştir. DOKA kapsamındaki 6 il için gerçekleştirilen çalışma sonucunda Giresun ili DOKA kapsamında kentsel rekabet seviyesi olarak kendisine 3. sırada yer bulmuştur.

Liu, Guo, Li, Li ve Pan (2016), yazmış oldukları makalede Çin'in Yangtze Nehri Deltası'nda yer alan on şehrin kentsel rekabet gücünü ölçmüşlerdir. Çalışmada 2006 ile 2009 yılları arası veriler kullanılmış olup çalışma sonucunda Suzhou şehri on şehir arasında kentsel rekabet gücü en yüksek şehir olarak tespit edilmiştir.

\section{VERI SETI VE YÖNTEM}

Çalışmada TR83 bölgesinde yer alan iller olan Amasya, Çorum, Samsun ve Tokat'ın kentsel rekabet edebilirlik seviyelerini belirleme kapsamında benzer çalışmalardan faydalanılarak beşeri sermaye ve yaşam kalitesi, markalaşma yeteneği ve yaratıcılık, ticaret becerisi ve erişilebilirlik olmak üzere dört alt endeks belirlenmiştir. Yine bu 4 alt endeks kapsamında 35 değişkene yer verilmiştir.

Beşeri sermaye ve yaşam kalitesi endeksine dair kullanılan değişkenler Tablo 1'de, markalaşma becerisi ve yaratıcılık endeksi kapsamında kullanılan değişkenler Tablo 2'de, ticaret becerisi alt endeksi içerisinde yer alan değişkenler Tablo 3'te ve erişilebilirlik endeksi çerçevesinde çalışmada yer alan değişkenler Tablo 4'te görülmektedir.

Çalışmada kullanılan değişkenlere ait veriler 2015 yılına aittir. 2015 yılı verileri baz alınarak endeks değerleri hesaplanmıştır. Çalışmada kullanılan değişkenlere ait verilerin güncel olarak ulaşılabildiği yıl 2015 yılı olduğu için 2015 yılına dair veriler kullanılmıştır. Çalışmada ilk olarak toplanan veriler normalize edilecek, daha sonrasında belirtilen formüllerle TR83 bölgesinde yer alan her bir ile ait beşeri sermaye ve yaşam kalitesi endeksi, markalaşma yeteneği ve yaratıcılık endeksi, ticaret becerisi endeksi ve erişilebilirlik endeksi hesaplanacaktır. Daha sonra ise bu alt endekslerin ortalaması alınarak her bir il için kentsel rekabet edebilirlik endeks değerleri ortaya konulacaktır. 
Toplanan veriler ilk etapta normalize edilmiştir. Normalize edilme işlemi esnasında kullanılan denklem aşağıdaki gibidir.

$$
\text { Normalize } X=100 * \frac{(X-\text { Değişkene ait minimum değer })}{\text { (Değişkene ait maksimum değer }- \text { Değişkene ait minimum değer })}
$$

$\mathrm{Bu}$ kapsamda normalize edilmesi talep edilen il için ilgili değişken değerine $\mathrm{X}$ denilmiştir. $\mathrm{Bu} \mathrm{X}$ değerinden ilgili değişkene ait minimum değer çıkartılarak pay elde edilmektedir. Daha sonra da ilgili değişkene ait maksimum değerden minimum değer çıkartılarak payda ortaya çıkmaktadır. Bölme işlemi sonucu çıkan değer 100'le çarpıldıktan sonra her ilin ilgili değişken kapsamında normalize edilmiş değerine ulaşılmaktadır. Gerçekleştirilen bu işlem sonrasında değişken değeri 100 olan il en yüksek puanı almakta iken değişken değeri 0 olan il ise en düşük değeri almaktadır.

Verilerin normalize edilme işlemi sonrasında kentsel rekabet edebilirlik endeksi altında yer alan 4 ana değişken olan beşeri sermaye ve yaşam kalitesi, markalaşma becerisi ve yaratıcılık, ticaret becerisi ve erişilebilirlik endeks değerlerinin elde edilmesi gerekmektedir. $\mathrm{Bu}$ kapsamda aşağıdaki formül kullanılmaktadır.

$$
\begin{gathered}
\text { Endekst }=\left(\frac{\sum i A_{t i} X_{t i}}{\sum i\left|A_{t i}\right|}\right) \\
A_{t i}=t \text { ana değişkeninin } i^{\prime} \text { inci alt değişkeninin ağırlı̆̆ } \\
X_{t i}=t \text { ana değişkeninin } i^{\prime} \text { inci alt değişkeninin normalize edilmiş değer } i
\end{gathered}
$$

Endeks değeri tespit edilecek olan il 'Endeks t' ile gösterilmiştir. Denklemin pay kısmında iller için normalize edilme işlemi gerçekleştirilmiş olan iller tek tek kendi ağırlıkları ile çarpılmakta ve daha sonra bu değerlerin toplamı alınmaktadır. Payda kısmında ise ana değişkende yer alan değişkenlerin ağırlık değerlerinin toplamı yer almaktadır. Her bir il için bu işlemler gerçekleştirildikten sonra illere ait beşeri sermaye ve yaşam kalitesi endeksi, markalaşma becerisi ve yaratıcılık endeksi, ticaret becerisi endeksi ve erişilebilirlik endeksi değerlerine ulaşı1mış olunacaktır. Bu endeks değişkenlerine ulaşıldıktan sonra bu dört endeks değerinin ortalaması alınarak her bir il için kentsel rekabet edebilirlik endeks değerlerine ulaşılabilmektedir. Aşağıdaki formül kullanılarak kentsel rekabet edebilirlik endeks değerleri elde edilmiştir.

$$
\text { Kentsel Rekabet Edebilirlik Endeksi }=\frac{(B S Y K E+M Y Y E+T B E+E E)}{4}
$$

Formülasyonda verilen BSYKE, Beşeri Sermaye ve Yaşam Kalitesi Endeksini; MYYE, Markalaşma Yeteneği ve Yaratıcılık Endeksini; TBE, Ticaret Becerisi Endeksini ve EE ise Erişilebilirlik Endeksini işaret etmektedir.

\section{BULGULAR}

Belirlenen 4 ana değişken olan Beşeri Sermaye ve Yaşam Kalitesi, Markalaşma Yeteneği ve Yaratıcılık, Ticaret Becerisi ve Erişilebilirlik kapsamında analiz gerçekleştirilmiştir. TR83 Bölgesinde yer alan Amasya, 
Çorum, Samsun ve Tokat gibi illerin bu endeks değerlerine ulaşıldıktan sonra her bir il için bu dört endeksin aritmetik ortalaması alınarak kentsel rekabet edebilirlik endeksi değerlerine ulaşılmıştır.

\section{A.Beşeri Sermaye ve Yaşam Kalitesi Değişkeni ve Alt Değişkenlerine Dair Bulgular}

Kentsel rekabet edebilirliğin önemli unsurlarından olan beşeri sermaye ve yaşam kalitesine yönelik endeks değerini belirleme amacıyla çalışmada Yükseköğrenim Programından mezun olan kişi sayıs1, mesleki ve teknik okuldan mezun olan kişi sayısı, kişi başına düşen hastane yatağı sayısı, kişi başına düşen mevduat miktarı, YGS puan ortalaması, kişi başına düşen otomobil sayısı, şehirleşme oranı, 5 yıldızlı otel bulunması, Süper Lig veya 1. Lig takımı bulunması, AVM bulunması ve işlenen suç nedeniyle kişi başına ceza infaz kurumuna giren hükümlü sayısı olmak üzere 11 değişken kullanılmıştır. Tablo 1 'de beşeri sermaye ve yaşam kalitesi değişkeni kapsamında kullanılan alt değişkenler ve bu değişkenlerin ağırlıkları yer almaktadır.

Tablo 1. Beşeri Sermaye ve Yaşam Kalitesi Endeks Değişkenleri

\begin{tabular}{|c|c|c|}
\hline Değişken & $\begin{array}{l}\text { Değişkenin } \\
\text { Ağırlığı }\end{array}$ & Hesaplama Yöntemi \\
\hline $\begin{array}{l}\text { Yükseköğrenim Programından Mezun Olan } \\
\text { Kişi Sayısı }\end{array}$ & 5 & $\begin{array}{l}\text { İl Kapsamında Yükseköğrenim } \\
\text { Kurumlarından Mezun Sayısı }\end{array}$ \\
\hline $\begin{array}{l}\text { Mesleki ve Teknik Okuldan Mezun Olan Kişi } \\
\text { Sayısı }\end{array}$ & 5 & $\begin{array}{c}\text { İl Kapsamında Mesleki ve Teknik Okul } \\
\text { Mezun Sayısı }\end{array}$ \\
\hline Kişi Başına Düşen Hastane Yatağı Sayıs1 & 4 & İldeki Hastane Yatağ1 Sayısı/İl Nüfusu \\
\hline Kiși Başına Düşen Mevduat Miktarı & 4 & İldeki Mevduat Miktarı/İl Nüfusu \\
\hline YGS Puan Ortalamas1 & 3 & İl Bazında YGS Puan Ortalaması \\
\hline Kiși Başına Düşen Otomobil Sayısı & 3 & İldeki Otomobil Sayısı/İl Nüfusu \\
\hline Şehirleşme Oranı & 3 & $\begin{array}{c}\text { İl ve İlçe Merkezi Nüfusu/İlin Toplam } \\
\text { Nüfusu }\end{array}$ \\
\hline 5 Yıldızlı Otel Bulunması & 2 & $\begin{array}{c}\text { İlde } 5 \text { yıldızlı otel varsa } 1 \text {, yoksa } 0 \\
\text { verilmiştir. }\end{array}$ \\
\hline Süper Lig veya 1.Lig Takımı Bulunması & 2 & $\begin{array}{l}\text { İlde Süper Lig takımı varsa } 1 \text {, } 1 \text {. Ligde } \\
\text { takımı olan şehirlere } 0,5 \text {, her iki ligde de } \\
\text { takımı olmayan şehirlere } 0 \text { verilmiştir. }\end{array}$ \\
\hline AVM bulunması & 2 & İlde AVM varsa 1 , yoksa 0 verilmiștir. \\
\hline $\begin{array}{l}\text { İşlenen Suç Nedeniyle Kişi Başına ceza infaz } \\
\text { kurumuna giren hükümlü sayısı }\end{array}$ & -3 & $\begin{array}{c}\text { Suçun İşlendiği İle Göre ceza evine giren } \\
\text { hükümlü sayıs//Il Nüfusu }\end{array}$ \\
\hline
\end{tabular}

Tablo 2'ye bakıldığında T83 Bölgesi'nde yer alan illerin beşeri sermaye ve yaşam kalitesi endeksi kapsamında normalize edilmiş değerleri bulunmaktadır. Tokat ilinin sonuçlarına baktığımızda belirtilen dört il içerisinde Tokat ilinin kişi başına düssen mevduat miktarı, 5 yıldızlı otel bulunması ve Süper Lig veya 1 . Lig'de futbol takımı bulunması değişkenleri kapsamında 0 puana sahip olduğu görülmektedir. Sadece AVM bulunması değişkeni kapsamında 100 puanı bulunmaktadır. Tokat ili, Yükseköğretim programlarından mezun olan kişi sayısı, mesleki ve teknik okuldan mezun kişi sayısı, kişi başına düşen hastane yatağı sayısı, şehirleşme oranı gibi değişkenlerde ise Samsun ilinin ardından 2. sırada gelmektedir. 
Tablo 2. TR83 Bölgesi'nde Yer Alan İllerin Beşeri Sermaye ve Yaşam Kalitesi Endeksi

Kapsamında Normalize Edilmiş Değerleri

\begin{tabular}{|l|c|c|c|c|}
\hline Değişken & Amasya & Çorum & Samsun & Tokat \\
\hline Yükseköğrenim Programından Mezun Olan Kişi Sayısı & 8,29 & 0 & 100 & 44,53 \\
\hline Mesleki ve Teknik Okuldan Mezun Olan Kişi Sayısı & 0 & 9,62 & 100 & 30,36 \\
\hline Kişi Başına Düşen Hastane Yatağ1 Sayısı & 0 & 50 & 100 & 60 \\
\hline Kişi Başına Düşen Mevduat Miktarı & 56 & 88 & 100 & 0 \\
\hline YGS Puan Ortalaması & 0 & 92,72 & 100 & 50,90 \\
\hline Kişi Başına Düşen Otomobil Sayısı & 100 & 69,12 & 0 & 10,06 \\
\hline Şehirleşme Oranı & 0 & 10,73 & 100 & 19,79 \\
\hline 5 Yıldızlı Otel Bulunması & 0 & 100 & 100 & 0 \\
\hline Süper Lig veya 1.Lig Takımı Bulunması & 0 & 0 & 50 & 0 \\
\hline AVM bulunması & 100 & 100 & 100 & 100 \\
\hline $\begin{array}{l}\text { Isşlenen Suç Nedeniyle Kişi Başına ceza infaz kurumuna } \\
\text { giren hükümlü sayısı }\end{array}$ & 53,33 & 100 & 0 & 46,66 \\
\hline
\end{tabular}

\section{B.Markalaşma Yeteneği ve Yaratıcılık Değişkeni ve Alt Değişkenlerine Dair Bulgular}

TR83 Bölgesi'nde yer alan illerin markalaşma yeteneği ve yaratıcılık endeks değerini tespit etmek adına patent tescil sayısı, marka tescil sayısı, faydalı model tescil sayıs1 ve endüstriyel tasarım tescil oranı olmak üzere dört alt değişkene yer verilmiştir. Bu değişkenler ve değişkenleri ağırlıkları aynı zamanda Tablo 3'de görülmektedir.

Tablo 3. Markalaşma Yeteneği ve Yaratıcılık Endeks Değişkenleri

\begin{tabular}{|l|c|c|}
\hline Değişken & $\begin{array}{c}\text { Değişkenin } \\
\text { Ăğırlığı }\end{array}$ & Hesaplama Yöntemi \\
\hline Patent Tescil & 5 & Son beş yıla ait patent tescil ortalaması \\
\hline Marka Tescil & 5 & Son beş yıla ait marka tescil Ortalaması \\
\hline Faydalı Model Tescil & 4 & $\begin{array}{c}\text { Son beş yıla ait faydalı model tescil } \\
\text { ortalaması }\end{array}$ \\
\hline Endüstriyel tasarım tescil ortalaması & 4 & $\begin{array}{c}\text { Son beş yılın endüstriyel tasarım tescil } \\
\text { ortalaması }\end{array}$ \\
\hline
\end{tabular}

Belirtilen formüllerle gerçekleştirilen hesaplamalar sonrası Tablo 4'de normalize edilmiş olan verilere bakıldığında Tokat ilinin faydalı model tescil sayısı ve endüstriyel tasarım tescil ortalaması alanlarında en düşük değere sahip olduğu görülmektedir. Tokat ilinin belirtilen değişkenler içerisinde en yüksek değeri 9,94 ile marka tescil alanında elde ettiği gözlemlenmektedir. Yine patent tescili kapsamında 7,69 puanı bulunmaktadır.

Tablo 4. TR83 Bölgesi’nde Yer Alan İllerin Markalaşma Yeteneği ve Yaratıcılık Endeksi Kapsamında Normalize Edilmiş Değerleri

\begin{tabular}{|l|c|c|c|c|}
\hline Değişken & Amasya & Çorum & Samsun & Tokat \\
\hline Patent Tescil & 0 & 65,38 & 100 & 7,69 \\
\hline Marka Tescil & 0 & 26,54 & 100 & 9,94 \\
\hline Faydalı Model Tescil & 4,91 & 59,01 & 100 & 0 \\
\hline Endüstriyel tasarım tescil ortalaması & 35,31 & 46,03 & 100 & 0 \\
\hline
\end{tabular}

\section{C.Ticaret Becerisi Değişkeni ve Alt Değişkenlerine Dair Bulgular}

Ticaret becerisi ana değişkeni kapsamında illerde kullanılan kredi miktarı, tahakkuk eden vergi miktarı, ihracat hacmi, dış ticaret hacmi, sanayi elektrik tüketim miktarı, kişi başına açılan şirket sayısı, kamu yatırımları (ulaştırma- 
haberleştirme sektörleri hariç), gümrük bulunması, iç talep potansiyeli, yatırım teşvik belgesi verilen sabit yatırım miktarı ve kişi başına kapanan şirket sayısı olmak üzere 11 alt değişkene yer verilmiştir. Bu değişkenler ve ağırlıkları Tablo 5 'de görülmektedir.

Tablo 5. Ticaret Beceri Endeks Değişkenleri

\begin{tabular}{|l|c|c|}
\hline Değişken & $\begin{array}{c}\text { Değişkenin } \\
\text { A ğırlığı }\end{array}$ & Hesaplama Yöntemi \\
\hline Kullanılan Kredi Miktarı & 5 & İlde Kullanılan Kredi Miktarı \\
\hline Tahakkuk Eden Vergi Miktarı & 5 & İlde Tahakkuk Eden Vergi Miktarı \\
\hline İhracat Hacmi & 5 & $\begin{array}{c}\text { İlde Kayıtlı Firmalar Tarafindan } \\
\text { Gerçekleştirilen İhracat Toplamı }\end{array}$ \\
\hline Dış Ticaret Hacmi & 5 & $\begin{array}{c}\text { İlde Gerçekleştirilen İhracat ve İthalat } \\
\text { Toplamı }\end{array}$ \\
\hline Sanayi Elektrik Tüketim Miktarı & 5 & İlde Sanayide Tüketilen Elektrik Miktarı \\
\hline Kişi Başına Açılan Şirket Sayısı & 5 & $\begin{array}{c}\text { İlde Kişi Başına Açılan Şirket } \\
\text { Sayısi/Türkiye genelinde kişi başına açılan } \\
\text { şirket sayısı }\end{array}$ \\
\hline Kamu Yatırımları & 3 & $\begin{array}{c}\text { İldeki Toplam Kamu Yatırımları (Enerji ve } \\
\text { Ulaştırma-Haberleştirme Sektörleri Hariç) }\end{array}$ \\
\hline Gümrük Bulunması & 3 & $\begin{array}{c}\text { İlde Gümrük bulunuyorsa 1, bulunmuyorsa } 0 \\
\text { değeri verilmiştir. }\end{array}$ \\
\hline İç Talep Potansiyeli & 3 & İlin toplam nüfusu/Türkiye toplam nüfusu \\
\hline $\begin{array}{l}\text { Yatırım teşvik belgesi verilen sabit yatırım } \\
\text { miktarı }\end{array}$ & 2 & $\begin{array}{c}\text { İl bazında yatırım teşvik belgesi verilen sabit } \\
\text { yatırım miktarı }\end{array}$ \\
\hline Kişi Başına Kapanan Şirket Sayısı & -5 & $\begin{array}{c}\text { İlde Kişi Başına Kapanan Şirket } \\
\text { Sayısi/Türkiye genelinde kişi başına } \\
\text { kapanan şirket sayısı }\end{array}$ \\
\hline
\end{tabular}

Gerçekleştirilen hesaplamalar neticesinde Tokat ilinin ihracat hacmi, diş ticaret hacmi, kişi başına açılan şirket sayısı, gümrük bulunması, yatırım teşvik belgesi verilen sabit yatırım miktarı ve kişi başına kapanan şirket sayısı değerlerinin 0 olduğu görülmektedir. Kişi başına kapanan şirket sayısı kapsamında 0 değeri, değişken ağırlı̆̆ına da bakıldığında Tokat ili için olumlu bir avantaj iken diğer değişkenlerde elde edilen 0 puan ise Tokat'ın ticaret yeteneği ana değişkeni kapsamında hanesine olumsuz yansıyan unsurlardır. Tokat bu alanda en yüksek puanı 28,68 ile iç talep potansiyeli değişkeninde elde etmiştir.

Tablo 6. TR83 Bölgesi'nde Yer Alan İllerin Ticaret Becerisi Endeksi Kapsamında Normalize Edilmiş Değerleri

\begin{tabular}{|l|c|c|c|c|}
\hline Değişken & Amasya & Çorum & Samsun & Tokat \\
\hline Kullanılan Kredi Miktarı & 0 & 24,009 & 100 & 10,64 \\
\hline Tahakkuk Eden Vergi Miktarı & 0 & 7,07 & 100 & 3,64 \\
\hline İhracat Hacmi & 17,57 & 83,99 & 100 & 0 \\
\hline Dış Ticaret Hacmi & 6,69 & 56,97 & 100 & 0 \\
\hline Sanayi Elektrik Tüketim Miktarı & 0 & 7,74 & 100 & 8,39 \\
\hline Kişi Başına Açılan Şirket Sayısı & 64,28 & 100 & 100 & 0 \\
\hline Kamu Yatırımları (Ulaştırma-Haberleşme Sektörü Hariç) & 0 & 48,73 & 100 & 10,02 \\
\hline Gümrük Bulunması & 0 & 100 & 100 & 0 \\
\hline İç Talep Potansiyeli & 0 & 21,31 & 100 & 28,68 \\
\hline Yatırım teşvik belgesi verilen sabit yatırım miktarı & 4,7 & 7,46 & 100 & 0 \\
\hline Kişi Başına Kapanan Şirket Sayısı & 0 & 75 & 100 & 0 \\
\hline
\end{tabular}




\section{D.Erişilebilirlik Değişkeni ve Alt Değişkenlerine Dair Bulgular}

Çalışmada erişilebilirlik ana değişkeni kapsamında kullanılmak üzere kişi başına düşen geniş bant internet aboneliği sayısı, kişi başına düşen sabit telefon hatt1 aboneliği sayısı, hava trafiğine açık havalimanı bulunması, otoyol ağına bağlı olma durumu, demiryolu ağına bağlı olma durumu, liman bulunması, haberleşme-ulaşım sektörlerinde kamu yatırımları, kilometre kare başına düşen bölünmüş yol uzunluğu ve kilometre kare başına düşen araç sayısı olmak üzere 9 alt değişkenin ele alındığı Tablo 7'de gözlemlenmektedir.

Tablo 7. Erişilebilirlik Endeks Değişkenleri

\begin{tabular}{|l|c|c|}
\hline Değişken & $\begin{array}{c}\text { Değişkenin } \\
\text { Ağırlığı }\end{array}$ & Hesaplama Yöntemi \\
\hline $\begin{array}{l}\text { Kişi Başına Düşen Geniş bant İnternet } \\
\text { Aboneliği Sayısı }\end{array}$ & 5 & İldeki Geniş bant Abone Sayısı/İl Nüfusu \\
\hline $\begin{array}{l}\text { Kişi Başına Düş̧ Sabit Telefon Hattı } \\
\text { Aboneliği Sayısı }\end{array}$ & 5 & $\begin{array}{c}\text { İldeki Sabit Telefon Hattı Abone Sayısı/İl } \\
\text { Nüfusu }\end{array}$ \\
\hline $\begin{array}{l}\text { Hava trafiğine açık Havalimanı bulunması } \\
\text { Otoyol Ağına Bağlı Olma Durumu }\end{array}$ & 5 & $\begin{array}{c}\text { Havaalanı bulunan ile 1, havaalanı bulunan } \\
\text { ile en çok 80 km mesafe bulunan ile 0,5 } \\
\text { ilde havaalanı yoksa 0 verilmiştir. }\end{array}$ \\
\hline $\begin{array}{l}\text { Demiryolu Ağına Bağlı Olma Durumu } \\
\text { İl otoyol ağına bağlıysa 1, bağlı değilse 0 } \\
\text { verilmiştir. }\end{array}$ & $\begin{array}{c}\text { İl demiryolu ağına bağlıysa 1, bağlı değilse } \\
\text { 0 verilmiştir. }\end{array}$ \\
\hline $\begin{array}{l}\text { Liman bulunması } \\
\text { Haberleşme-Ulaştırma Sektöründe Kamu } \\
\text { Yatırımları }\end{array}$ & 5 & $\begin{array}{c}\text { İlde liman varsa 1,il liman bulunan ile en } \\
\text { çok 80 km uzaklıktaysa 0,5, ilde liman } \\
\text { yoksa 0 verilmiştir. }\end{array}$ \\
\hline $\begin{array}{l}\text { Kilometre kare başına düşen bölünmüş yol } \\
\text { uzunluğu }\end{array}$ & 3 & $\begin{array}{c}\text { İlde haberleşme ve ulaşım sektörlerine } \\
\text { yapılan kamu yatırımları }\end{array}$ \\
\hline Kilometre kare başına düşen araç sayısı & -3 & $\begin{array}{c}\text { İldeki bölünmüş yol uzunluğu/İlin } \\
\text { yüzölçümü }\end{array}$ \\
\hline
\end{tabular}

Gerçekleştirilen hesaplamalar neticesinde Tokat ilinin hava trafiğine açık havalimanı bulunması ve demiryolu ağına bağlı olma durumu kapsamında 100 puanı olduğu görülmektedir. Kişi başına düşen geniş bant internet aboneliği sayıs1, kişi başına düşen sabit telefon hattı aboneliği sayısı, otoyol ağına bağlı olma durumu ve liman bulunması değişkenlerinde 0 puanı olduğu gözlemlenmektedir.

Tablo 8. TR83 Bölgesi’nde Yer Alan İllerin Erişilebilirlik Endeksi Kapsamında Normalize Edilmiş Değerleri

\begin{tabular}{|l|c|c|c|c|}
\hline Değişken & Amasya & Çorum & Samsun & Tokat \\
\hline Kiși Başına Düşen Geniș bant İnternet Aboneliği Sayısı & 100 & 14,56 & 38,85 & 0 \\
\hline Kişi Başına Düşen Sabit Telefon Hattı Aboneliği Sayısı & 100 & 17,91 & 63,88 & 0 \\
\hline Hava trafiğine açı Havalimanı bulunması & 100 & 50 & 100 & 100 \\
\hline Otoyol Ağına Bağlı Olma Durumu & 0 & 0 & 0 & 0 \\
\hline Demiryolu Ağına Bağlı Olma Durumu & 100 & 0 & 100 & 100 \\
\hline Liman bulunması & 0 & 0 & 100 & 0 \\
\hline Haberleșme-Ulaştırma Sektöründe Kamu Yatırımları & 0 & 38,75 & 100 & 0,15 \\
\hline Kilometre kare başına düşen bölünmüş yol uzunluğu & 100 & 0 & 35,6 & 3,66 \\
\hline Kilometre kare başına düşen araç sayısı & 27,15 & 0 & 100 & 16,23 \\
\hline
\end{tabular}




\section{E.TR83 Bölgesi'nde Yer Alan İllerin Kentsel Rekabet Edebilirlik Endeks Değerleri}

Çalışmada kentsel rekabet edebilirlik endeksi kapsamında kullanılmak üzere beşeri sermaye ve yaşam kalitesi endeksi, markalaşma yeteneği ve yaratıcılık endeksi, ticaret becerisi endeksi ve erişilebilirlik endeksi olmak üzere 4 alt endeks oluşturulmuştur.

Tablo 9' da TR83 Bölgesinde yer alan Amasya, Çorum, Tokat ve Samsun gibi illerin Beşeri Sermaye ve Yaşam Kalitesi Endeksi, Markalaşma Yeteneği ve Yaratıcılık Endeksi, Ticaret Becerisi Endeksi ve Erişilebilirlik Endeksi ve nihai olarak Kentsel Rekabet Edebilirlik Endeks değerleri yer almaktadır.

Tablo 9. TR83 Bölgesi'nde yer alan illerin Kentsel Rekabet Edebilirlik Endeks Değerleri

\begin{tabular}{|l|c|c|c|c|}
\hline Endeksler & Amasya & Çorum & Samsun & Tokat \\
\hline Beşeri Sermaye ve Yaşam Kalitesi & 19,53 & 42,51 & 96,77 & 29,57 \\
\hline Markalaşma Yeteneği ve Yaratıcılık & 8,93 & 48,87 & 100 & 4,89 \\
\hline Ticaret Becerisi & 12,55 & 43,02 & 100 & 6,37 \\
\hline Erişilebilirlik & 67,22 & 16,01 & 64,25 & 29,17 \\
\hline KENTSEL REKABET EDEBíLiRLİK & $\mathbf{2 7 , 0 5}$ & $\mathbf{3 7 , 6 0}$ & $\mathbf{9 0 , 2 5}$ & $\mathbf{1 7 , 5 0}$ \\
\hline
\end{tabular}

Tablo 9'a bakıldığında bu dört il içerisinde kentsel rekabet edebilirlik endeks değeri en yüksek olan ilin 90,25 puanla Samsun olduğu görülmektedir. Samsun'u 37,60 puanla Çorum ve daha sonrasında ise 27,05 puanla Amasya ilinin takip ettiği görülmektedir. Tokat ilinin ise 17,50 puanla son sirada yer aldığ gözlemlenmektedir.

Tokat ilinin genel endeks ve 4 alt endeks sıralaması kapsamında değerlendirme yapılması gerekirse Tokat ilinin kentsel rekabet edebilirlik endeksi kapsamında son sırada yer aldığı görülmektedir. Tokat ilinin kentsel rekabet edebilirlik endeks değerine en çok katkı sağlayan alan olan beşeri sermaye ve yaşam endeksi kapsamında 29,57 puanla TR83 bölgesi illeri içerisinde üçüncü sırada yer aldığı görülmektedir. Ticaret becerisi endeksi kapsamında 6,37 puanla son sırada ve markalaşma yeteneği ve yaratıcılık endeksi kapsamında da 4,89 puanla yine son sırada yer almaktadır. Tokat ili erişilebilirlik endeks değeri kapsamında ise 29,17 puan ile TR83 Bölgesi illeri içerisinde 3. Sirada yer almaktadir.

Tokat ilinin kentsel rekabet edebilirlik endeks değerine en çok katkı sağlayan değişkenler sırasıyla beşeri sermaye ve yaşam kalitesi ve erişilebilirlik olmuş̧ur. Tokat ilinin kentsel rekabet edebilirlik endeks değerine en az katkııı ise markalaşma yeteneği ve yaratıcılık değişkeni sağlamıştır.

\section{SONUÇ}

Kentlerin rekabet edebilirlik göstergeleri, bölgesel olarak kalkınmaya ve nihayetinde makroekonomik göstergelerine etki ederek ülke ekonomilerine olumlu katkıda bulunabilmektedir. İktisadi yapı kapsamında temel bir birim olarak şehirler, ülkelerin büyümeleri üzerinde itici bir güç olabilmektedirler.

Rekabetçi kentlerin tesis edilmesi hususunda yerel yönetimlere ve hükümetlere de önemli görevler düşmektedir. Yerel yönetimler veya hükümetler, 
kentlerin rekabetçilik yönlerini geliştirecek şekilde projeler üretmeli, kamu yatırımlarını bu kapsamda gerçekleştirmelidirler.

TR83 Bölgesinde yer alan iller içerisinde Tokat ilinin rekabet edebilirlik seviyesinin araştırılmasını amaçlayan bu çalışma kapsamında 2015 yılı verileri kullanılarak kentsel rekabet edebilirlik endeksi oluşturulmuş ve bu kapsamda analiz gerçekleştirilmiştir.

Analiz sonucunda Tokat ilinin kentsel rekabet edebilirlik endeks değerinin diğer illerin endeks değerlerinin gerisinde kaldığı görülmektedir. Gerçekleştirilen hesaplamalar neticesinde Tokat ilinin beşeri sermaye ve yaşam endeks değeri 29,57, markalaşma yeteneği ve yaratıcılık endeks değeri 4,89, ticaret becerisi endeks değeri 6,37 ve erişilebilirlik endeks değerinin de 29,17 olduğu görülmektedir. Nihai olarak ise Tokat ilinin kentsel rekabet edebilirlik endeks değeri 17,50 çıkmıştır.

Kentsel rekabet edebilirlik endeksini oluşturan ana değişkenler kapsamında Tokat ilinin 29,57 puanla en başarılı olduğu alanın beşeri sermaye ve yaşam endeksi olduğu gözlemlenmektedir. Beşeri sermaye ve yaşam kalitesi ana değişkenini ise 29,17 puanla erişilebilik değişkeni izlemektedir. Tokat ilinin düşük puan elde ettiği kısımlar ise 6,37 ile ticaret becerisi ve 4,89 ile markalaşma yeteneği ve yaratıcılık endeksidir. Çalışma sonucunda Tokat ili markalaşma yeteneği ve yaratıc1lık ve ticaret becerisi endekslerinde TR83 Bölgesi illeri içerisinde son sırada yer almıştır. Keza kentsel rekabet edebilirlik endeks değerlerinde de diğer illerin gerisinde kalmıştır.

Tokat ilinin markalaşma yeteneği ve yaratıc1lık değişkeni çerçevesinde şehrin tanıtımının yeterli oranda yapılmadığ 1 ve bu amaç doğrultusunda harekete geçilmediği analiz sonuçlarından anlaşılmaktadır. Şehirdeki coğrafi işaretlerin tanıtımına yönelik faaliyetler gerçekleştirilmeli, sahip olunan kültürel zenginlikler açığa çıkarılarak marka tescili kapsamında değerlendirilmelidir. Yöreye ait varlıklar markalaştıılmalıdır. Şehirde inovasyon odaklı seminerler yaygınlaştırılarak bilgi ekonomisi kapsamında Tokat'ın çağdaş bir olması için gerekli olan çalışmalar gerçekleştirilmelidir.

Yine ticaret becerisi kapsamında TR83 bölgesi içerisinde son sırada yer alan Tokat ili, bu kapsamda ilerleme katedebilmek için ilk olarak Tokat ilinin dış ticaret hacminin artırılmasına yönelik girişimlerde bulunmalıdır. Şehre yönelik gerçekleşen kamu yatırımlarının artırılmasına yönelik çabalarda bulunulmalıdır. Eskiden var olan fakat daha sonradan kapatılan gümrügün tekrardan yöreye tahsisi hususunda çalışmalar yapılmalıdır. Tokat Organize Sanayi Bölgesi'nin gelişimine yönelik teşviklerin artırılması hususunda girişimler gerçekleştirilmelidir. OKA ve KOSGEB gibi kurumlar Tokat ili için daha fazla bütçe ödeneği ayırmalıdır.

Beşeri sermaye ve yaşam kalitesinin artırılmasına yönelik olarak sağlık ve eğitim hizmetleri gibi önemli beşeri sermaye unsurlarının daha da geliştirilmesi için çaba sarf edilmelidir. Sportif faaliyetler desteklenmeli, hem gençleri kötü alışkanlıklardan korumak, hem de sağlıklı aktivitelerde bulunabilmeleri için spor okullarına kaydolmaları hususunda gençler teşvik edilmelidir. Bunun dışında 
şehre gelen veya gelme potansiyeli olan yerli ve yabancı turistler için konaklama kapsamında elverişli imkanlar oluşturulmalıdır. Şehirde var olan işsizlik problemine çare bulunması adına çalışmalar yerine getirilmelidir.

Erişilebilirlik değişmesi kapsamında ise Tokat ilinde internet kullanımının yaygınlaşması hususunda faaliyetler gerçekleştirilmeli, haberleşme ve ulaşım sektörüne yönelik gerçekleşebilecek kamu yatırımlarının artırılmasına yönelik çalışmalarda bulunulmalıdır.

Genel itibariyle yerel yöneticiler, Tokat ilinin kentsel rekabet edebilirliğinin artırılması için şehrin gelişimine etki edebilecek sektörlere yönelik kamu yatırımları gerçekleştirilmesi ve teşvikler sağlanması hususunda girişimlerde bulunmalı, şehrin sahip olduğu potansiyelin açığa çıkarılması konusunda çalışmalar gerçekleştirilmelidir.

\section{KAYNAKÇA}

Ak, D. (2013). Kentler Arası Rekabette İzmir'in Yeri, Ekonomi Bilimleri Dergisi, Cilt:5, No:1, s. 29-43.

Albayrak, A. ve Erkut, G. (2010). Türkiye'de Bölgesel Rekabet Gücü Analizi, Megaron, 5(3) :13748.

Alkin, K., Bulu, M. ve Kaya, H. (2007). İllerarası Rekabet Endeksi: Türkiye'deki İllerin Rekabetçilik Seviyelerinin Göreceli Olarak Ölçülebilmesi İçin Bir Yaklaşım, İstanbul Ticaret Üniversitesi Sosyal Bilimler Dergisi, Cilt: 6(11), s.221-235.

Begg, I. (1999). Cities and Competitiveness, Urban Studies, Vol. 36, Nos 5-6, pp. 795-810.

Bruneckiene, J., Guzavicius, A. and Cincikaite, R. (2010). Measurement of Urban Competitiveness in Lithuania, Inzinerine Ekonomika-Engineering Economics, 21(5), 493-508.

Du, Q., Wang, Y., Ren, F., Zhao, Z., Liu, H., Wu, C., Li, L. and Shen, Y. (2014). Measuring and Analysis of Urban Competitiveness of Chinese Provincial Capitals in 2010 under the Constraints of Major Function-Oriented Zoning Utilizing Spatial Analysis, Sustainability, 6, 3374-3399.

Eroğlu, O. ve Yalçın, A. (2014). Yeni Bir Rekabet Formu Olan Kent Rekabetçiliğine Yönelik Literatür Taraması, Çankırı Karatekin Üniversitesi İktisadi ve İdari Bilimler Fakültesi Dergisi, Cilt: 4(1), s.19-42.

European Commission Directorate (2009). A Study on the Factors of Regional Competitiveness, A Draft Final Report for the European Commission Directorate-General Regional Policy.

Gordon, I. (1999). Internationalism and Urban Competition, Urban Studies, 36, pp. 1001-1027.

Guo, H., Liu, X., Li, Y., Wang, D. and Chen, X. (2015). Comparison Analysis and Evaluation of Urban Competitiveness in Chinese Urban Clusters, Sustainability, 7(4): 4425-4447.

Ildiko, L. A. (2009). Competitiveness of Human Capital in the countries of the Visegrád Group (V4), Challenges for Analysis of the Economy, the Businesses, and Social Progress International Scientific Conference, 19-21 November 2009, Szeged, Péter Kovács, Katalin Szép, Tamás Katona (editors).

İpek, S. ve Öksüz, M. (2015). Giresun İlinin Kentsel Rekabet Gücünün DOKA Kapsamında İncelenmesi ve Değerlendirilmesi, Yönetim ve Ekonomi, Cilt: 22, Sayı: 2, 635-649.

Kwon, S., Kim, J. and Oh, D. S. (2012). Measurement of Urban Competitiveness Based on Innovation Indicators in Six Metropolitan Cities in Korea, World Technopolis Review, 1(3), 177-185.

L'Hostis A. and Bozzani, S. (2010). Contactability Measures for Assessing Urban Competitiveness, Glasgow, European

Conference http://hal.archives-ouvertes.fr/hal-00565618/ (Erişim Tarihi: 10.02.2019)

Liu, X, Guo, H. , Li, Y., Li, Y. and Pan, W. (2016). Measuring the Urban Competitiveness of Chinese Cities Based on Multi-Attribute Decision Making Approach, Int. J. Sustainable Development, Vol. 19, No. 4, 315-341. 
Moradi, F., Saeideh Zarabadi, Z. S. and Majedi, H. (2018). An Explanation of City Branding Model in order to Promote City Competitiveness and Economic Growth by Using of F'ANP Model, Urban Economics and Management, 6(2(22)), 177-199

Morais, P; Migueis, V.L. and Camanho, A.S. (2013). Quality of Life Experienced by Human Capital: An Assessment of European Cities, Social Indicators Research, Volume 110, Issue 1, pp 187-206.

Papa, R. , Gargiulo, C., Franco, S. and Russo, L. (2014). Urban Smartness vs Urban Competitiveness A Comparison of Italian Cities Rankings, Journal of Land Use, Mobility and Environment, Special Issue, Eighth International Conference INPUT Smart City Planning for Energy, Transportation and Sustainability of the Urban System Naples, 4-6 June 2014.

Peng, L. and Zhanxin, M. (2011). The Evaluation of City Competitiveness in Shandong Province, Energy Procedia, 5, 472-476.

Pengfei N. and Qinghu, H. (2006). Comparative Research on the Global Urban Competitiveness, Chinese Academy for Social Sciences, Beijing.

Riza, M. ; Doratli, N. and Fasli, M. (2011). City Branding and Identity, Asia Pacific International Conference on Environment-Behaviour Studies, Salamis Bay Conti Resort Hotel, Famagusta, North Cyprus, 7-9 December 2011.

Shen, J. (2004). Urban Competitiveness and Urban Governance in the Globalizing World, Asian Geographer, 23(1-2), 19-36.

Sinkiene, J. (2009). City Competitiveness: Concept, Factors, Model, International Conference Current Issues in Management of Business and Society Development, Riga, 7 - 9 May 2009.

Tsaurkubule, Z. (2013). Influence of Quality of Life on the State and Development of Human Capital in Latvia, Contemporary Economics, 8 (1), pp. 103-112.

United Nations Conference on Trade and Development (2008). Creative Economy Report, http://unctad.org/en/Docs/ditc20082cer_en.pdf, (E.t. 13.02.2019).

\section{SUMMARY}

From the past to the present, it is seen that the concept of urban competition gains importance with the effect of globalization. Cities compete to attract more public investment and become a more developed city.

As the most basic unit within the economies, cities can specialize in different areas. Factors such as proximity to resources, population, human capital, labor force, infrastructure, technological development, geographical location, transportation, accessibility can be effective in the specialization of cities in different fields.

Governments play an important role in the development of cities. If resources and public investments are transferred to areas that are suitable for cities' specialization, cities can develop faster.

The aim of this study was to investigate the urban competitiveness of Tokat province within the scope of TR83 Region. In this context, urban competitiveness index was established by using similar studies and urban competitiveness levels of Tokat, Amasya, Çorum and Samsun provinces in TR83 Region were determined.

2015 data were used in the study. Within the scope of the urban competitiveness index, 4 main variables were identified and 25 variables were included in these four main variables. The main variables in the study are human 
capital and quality of life, branding ability and creativity, trade ability and accessibility.

The data collected in the study were normalized and then analyzed. After normalizing the data, index scores were obtained within the main variables of Tokat, Amasya, Çorum and Samsun provinces.

As a result of this analysis, Tokat province's human capital and quality of life index value of "29,57", branding ability and creativity index value "4,89", trade ability index value "6,37" and accessibility index value "29,17". were obtained. The most successful area of Tokat province is the human capital and quality of life with the index value of " 29,57 ".

Urban competitiveness index values of each province were calculated after each province's human capital and quality of life, branding ability and creativity, trade ability and accessibility index values were obtained.

According to the urban competitiveness index value, Tokat province was the last in TR83 Region. Within the scope of TR83 Region, the urban competitiveness value of Samsun province was determined as 90.25 and Samsun province was ranked 1st in the TR83 Region. Within the scope of the urban competitiveness index, Samsun province is followed by Çorum province with 37,60 points. Amasya was the third with 27.05 points and Tokat with 17.05 points.

Based on the results of the study, it is understood from the results of the analysis that the city's promotion was not done adequately within the framework of the branding ability and creativity variable of Tokat province and no action was taken for this purpose. Activities should be carried out to promote geographic signs that exist in the city and the cultural riches should be exposed and evaluated within the scope of trademark registration. Assets belonging to the region should be branded. Innovation-oriented seminars in the city should be expanded and necessary studies should be carried out in order to make Tokat a contemporary one.

Tokat, which is in the last place within TR83 region within the scope of trade capability, should first attempt to increase the foreign trade volume of Tokat province in order to progress in this context. Studies should be made on the allocation of the previously existing customs, which was later closed, to the region. Initiatives should be undertaken to increase incentives for the development of the Tokat Organized Industrial Zone.Institutions such as OKA and KOSGEB should allocate more budgetary appropriations for Tokat.

Efforts should be made to further develop important human capital elements such as health and education services in order to improve human capital and quality of life. Sportive activities should be supported, young people should be encouraged to enroll in sports schools to protect young people from bad habits and to have healthy activities. Apart from this, suitable facilities should be established for the domestic and foreign tourists who have the potential to come or come to the city. Work should be carried out in order to find a solution to the unemployment problem in the city. 
Within the scope of accessibility variable, activities should be carried out in order to increase the use of internet in Tokat and efforts should be made to increase public investments in the communication and transportation sector.

Generally, local administrators should make initiatives to provide public investments and incentives for the development of Tokat province in order to increase the urban competitiveness of the city, studies should be conducted to reveal the potential of the city. 